\title{
Erratum to: Extended Neoadjuvant Chemotherapy for Borderline Resectable Pancreatic Cancer Demonstrates Promising Postoperative Outcomes and Survival
}

\author{
J. Bart Rose, MD, MAS ${ }^{1}$, Flavio G. Rocha, MD ${ }^{1}$, Adnan Alseidi, MD ${ }^{1}$, Thomas Biehl, MD ${ }^{1}$, Ravi Moonka, MD ${ }^{1}$, \\ John A. Ryan, $\mathrm{MD}^{1}$, Bruce Lin, $\mathrm{MD}^{2}$, Vincent Picozzi, $\mathrm{MD}^{2}$, and Scott Helton, $\mathrm{MD}^{1}$ \\ ${ }^{1}$ Section of General, Thoracic and Vascular Surgery, Department of Surgery, Virginia Mason Medical Center, Seattle, WA; \\ ${ }^{2}$ Section of Medical Oncology, Department of Medicine, Virginia Mason Medical Center, Seattle, WA
}

\section{ERRATUM TO: ANN SURG ONCOL DOI 10.1245/S10434-014-3486-Z}

An error occurred in the Methods section, which is corrected here. The first sentence in the second paragraph, under the heading "Neoadjuvant Chemotherapy Regimen," should read:

Eligible patients were started on an eight-cycle course of $1,000 \mathrm{mg} / \mathrm{m}^{2}$ of gemcitabine and $40 \mathrm{mg} / \mathrm{m}^{2}$ of docetaxel given on days 1 and 8, every 21 days, with intermittent restaging by computed tomographic scan and cancer antigen (CA) 19-9 levels.

The sentence as originally published, "Eligible patients were started on an eight-cycle course of $1,000 \mathrm{mg} / \mathrm{m}^{2}$ of gemcitabine and $80 \mathrm{mg} / \mathrm{m}^{2}$ of docetaxel given on days 1 and 8 , every 21 days, with intermittent restaging by computed tomographic scan and cancer antigen (CA) 19-9 levels," is incorrect.

The online version of the original article can be found under doi:10.1245/s10434-014-3486-z.

(C) Society of Surgical Oncology 2014

Published Online: 17 March 2014

J. B. Rose, MD, MAS

e-mail: bart.rose@vmmc.org 